\title{
De Tróia a Vitória de Santo Antão: o fiel e a pedra entre a ética e a estética
}

\author{
Luiz Ernani Fritoli \\ Universidade Federal do Paraná
}

Com O Fiel e a Pedra encerra-se uma fase da minha atividade como escritor. (...) O Fiel e a Pedra representa, então, o ponto para o qual converge tudo o que eu fiz antes e o ponto de onde parte o que vim a fazer depois. É uma plataforma de chegada e de saída.

Osman Lins, Evangelho na Taba, p. 168.

\section{Entre a ética e a estética}

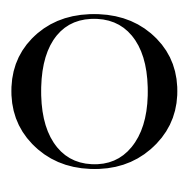

segundo romance de Osman Lins traz no cerne de sua história uma motivação diferente daquela de suas narrativas anteriores: a questão social do nordeste brasileiro, mais especificamente do interior de Pernambuco. Isso não significa que seus textos anteriores não trouxessem na superfície (claramente até) uma dimensão social crítica; o que queremos afirmar é simplesmente que o que antes era apenas esboçado para ser visível na superfície, n'O Fiel e a Pedra torna-se a espinha dorsal da trama, uma das duas linhas de força que percorrem o texto do começo ao fim, sem jamais relaxar a tensão. Esta linha de força é representada pelo drama social, verdadeira luta pela sobrevivência, do pobre casal Bernardo e Teresa diante da opressão do poderoso e inescrupuloso senhor de engenho Nestor Benício.

Essa situação coloca Bernardo constantemente diante de escolhas éticas entre a consciência e o compromisso. A primeira significa recusa à submissão e luta de morte com o opressor; o segundo significaria 
rendição da honra em troca de uma vida mais fácil para sua família. Mas essa é uma situação em que só aparentemente há uma possibilidade de escolha; sabemos, com Bernardo, desde o início, que não há escolha, não há rendição possível ao Mal. O conflito de Bernardo é um conflito interno contra a própria consciência, um conflito ético; mas é, ele o sabe, uma batalha perdida. Uma pedra pode ser lascada, esculpida, tomar formas, mas a essência é sempre uma, não deixa de ser pedra. Como personagem Bernardo é humano, não é um caráter, mas tem caráter; tem medo, tem desejos, comete erros, frustra-se, arrepende-se. Mas sua honra e sua dignidade humanas são aquelas de um Enéas, um caráter pétreo ${ }^{1}$.

Aliás, Enéas não é citado por acaso: essa é a segunda linha de força que molda a composição d' O Fiel e a Pedra, a linha mais puramente literária, que gera uma outra tensão para o leitor que a capta desde o início: a da expectativa em relação ao modelo, a Eneida. Toda a questão social se articula em torno da questão ética de Bernardo - entendendo ética como a parte da filosofia que se ocupa do problema moral, ou seja, do comportamento do homem em relação aos meios, aos fins e aos moventes de suas ações. Em outras palavras, trata da relação do indivíduo consigo mesmo, com os outros e com seu entorno. Mas o que importa para Osman Lins não é o juízo de valor, o julgamento moral; a crítica social é patente, mas é o valor literário aquele que predomina. Enquanto o fato social é argumento, o texto clássico é pré-texto, modelo sobre o qual erigir nova épica. Pela escolha dos nomes dos personagens e de algumas situações dramáticas, Osman Lins traz à tona como pré-texto o texto de Virgílio. Retomando temas do romance regionalista social da década de $30^{2}$, Lins

${ }^{1}$ Talvez exageradamente pétreo, se pensarmos que por causa da teimosa defesa de sua dignidade causa tanto sofrimento a outros. Bernardo parece jamais levar em consideração desejos ou opiniões de Teresa ou de quem quer que seja.

${ }^{2}$ Ver o que diz Massaud Moisés na "Introdução" à sexta edição (póstuma) d'O Fiel e a Pedra, São Paulo, Summus, 1979. Cfr. também: ADONIAS FILHO. O Romance Brasileiro de 30. Rio, Edições Bloch, 1969. Também ANDRADE, Ana Luiza, em seu livro Osman Lins: Crítica e Criação (São Paulo, Hucitec, 1987) menciona a semelhança temática d'O Fiel e a Pedra com Fogo Morto (1943), de José Lins do Rego e Bagaceira (1928), de José Américo de Almeida, ambos relativos ao período de decadência do ciclo canavieiro no Nordeste brasileiro. 
busca uma nova configuração para a ação de seu herói, seu Enéas sertanejo. Fiel a suas raízes geográficas, vai buscar no país sem fronteiras da literatura o modelo épico da Eneida, sobre o qual dimensiona ação e personagens d'O Fiel e a Pedra (sem, porém, forçar paralelismos antinaturais). Através dessa insólita associação obtém ao mesmo tempo dois grandes resultados: não cai na apatia da repetição insulsa de um modelo já tanto explorado (do romance regionalista tradicional), e reveste de um caráter mítico universalizante os elementos caseiros, domésticos, da pequena Vitória de Santo Antão, sua cidade natal, onde passou a infância e a adolescência. É a tensão entre a dimensão ética e a estética que sustenta a narrativa em um patamar literário superior.

Desse modo as mais "fisicamente simples" ações são elevadas a motivo de reflexão sobre a impotência do homem diante de forças superiores, diante da morte, diante dos limites do conhecimento e da ação. Seguindo o roteiro épico, acompanhamos a trajetória de Bernardo em suas viagens, seu exílio entre forçado e voluntário, suas batalhas e seu retorno à paz doméstica. Pelo paralelismo à saga de Enéas, Osman Lins dá ao texto uma dimensão de metafísica caseira de valor universal. O Fiel e a Pedra não deixa de ser um romance regionalista, pois retrata uma realidade social específica, com aquele colorido da terra, que não é igual em nenhum outro lugar. Mas não repete a fórmula que desgastou o romance regionalista dos anos 30, ou seja, o exagero do pitoresco, a folclorização da paisagem, dos tipos e da língua, a exploração do exótico dos mitos e lendas locais. Os personagens são, na maioria, pessoas humildes retratadas em seus afazeres quotidianos. Não são grandes heróis realizando grandes ações, não há aventuras empolgantes, mas simplesmente pessoas comuns realizando atividades comuns do dia-a-dia do povo brasileiro, em seu espaço próprio, nordestino em especial.

O modo de representação (ou seja, a dimensão estética) serve a um propósito artístico e social, mas não é o empenho social que orienta a criação artística, é antes a arte que reflete o fato social como pré-texto. Lins trata de uma realidade que é a que conheceu e que denuncia através de sua arte, mas não se deixa levar nem pela facilidade do tipicismo pitoresco nem pelo engajamento sócio-político anti-conformista e utilitarista. Buscando na rigidez formal clássica um modelo, compõe o romance com o rigor que é característico de toda sua obra. Toda a literatura de Osman Lins é séria, grave, cerebralmente controlada. 


\section{A ampliação do ethos}

Fiel à declaração de poética manifestada no "Prefácio" à segunda edição de Os Gestos , procura também n' O Fiel e a Pedra "lograr uma frase tão límpida quanto possível", uma frase transparente como o vitral mas esculpida na pedra, bem definida mas sem excessos. Tampouco há excessos aventurescos na ação dos personagens. Tudo no romance responde ao rigor conceitual do autor em relação à seriedade da literatura. Mas isso não significa que o estilo seja seco e árido; ao contrário, há momentos em que o texto atinge uma elevação lírica às fronteiras da poesia, inspirado pela atmosfera imposta pela escolha deliberada do modelo virgiliano. Inspirado também no modelo heróico virgiliano, pulsa no texto d' O Fiel e a Pedra, assim como nas veias de Bernardo, uma raiva controlada, pronta a explodir, estimulada pela consciência mas retida pela razão. Essa raiva contida de Bernardo é a raiva do povo oprimido, tanto mais justificada quanto mais racional se torna. É a mesma raiva do autor, pulsante e reprimida; sempre pronta a explodir e sempre contida. E que, assim como a obra de arte, só explodirá sob o rigor da forma. Assim a consciência social que se manifesta na obra literária, como obra de arte, no ápice de sua racionalidade ultrapassa os limites da denúncia e da revolta, e torna-se forma, numa explosão lenta e controlada, em que tempos e espaços são relativizados e dominados de um modo que só a literatura pode antecipar à física.

O domínio cada vez maior do espaço e do tempo narrativos é a conseqüência do amadurecimento da consciência do autor sobre o domínio dos próprios meios expressivos. Como seqüência a Os Gestos e O Visitante, O Fiel e a Pedra apresenta uma maior complexidade narrativa. $\mathrm{O}$ autor parece ter adquirido em grau elevado a consciência da realidade

\footnotetext{
${ }^{3}$ Nesse Prefácio, intitulado "O outro gesto", Osman define muito claramente sua filosofia de composição e objeto de sua busca estética: "Quando escrevi os contos aqui reunidos, todos alusivos ao tema da impotência (ante os elementos, ante os olhos de um morto, ante a linguagem etc), minha ambição centrava-se em dois itens: a) lograr uma frase tão límpida quanto possível; b) não alheio à voz de Aristóteles, fundir num instante único, privilegiado, os fios de cada breve composição, como se todo o passado ali se adensasse." LINS, Osman. Os gestos. 2. ed., São Paulo: Melhoramentos, 1975, p. 5.
} 
específica da matéria que é a obra literária, e ao mesmo tempo em que narra uma história, chama a atenção para o processo de narração, evocando como substrato paralelo ao texto a obra do maior dos escritores latinos. Edificando sobre terreno épico, Lins coloca sua pedra pernambucana sobre o espaço clássico, presentificando esse espaço e seus valores, redimensionando-os à realidade do povo nordestino do século XX, pobre, oprimido, mas tão humano quanto é possível a qualquer herói clássico.

Com O Fiel e a Pedra o autor como que refaz os próprios passos iniciais, retomando situações e temas já tratados anteriormente e aperfeiçoando-os (sem, porém, renegar o que já havia feito). Em relação a seus dois livros anteriores, neste texto os núcleos dramáticos evoluem da anterior predominância da análise psicológica e dos dramas internos dos personagens para uma amplitude social em que tal dimensão psicológica não é reduzida de importância, mas é inserida numa realidade ampliada em relação aos pequenos espaços de ação dos personagens precedentes.

Embora as cenas determinantes d'O Fiel e a Pedra ocorram em espaços bastante restritos, em que ganha importância especial a sala em que Bernardo e Teresa passavam as noites antes de se deitarem, há uma grande abertura de foco em relação às obras anteriores, que demonstravam uma preferência de Osman Lins pela casa fechada, pela sala ou quarto como quase único espaço de ação. A paisagem adquire uma importância

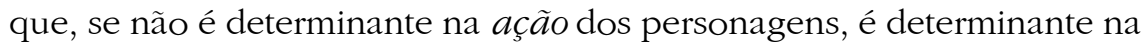
caracterização do tom do romance. O espaço d'O Fiel e a Pedra vai da cidade de Vitória de Santo Antão ao engenho do Surrão, de Nestor Benício, passando pela estrada muitas vezes percorrida por Bernardo. Há muitas descrições, quase sempre breves, mas que além de situar espacialmente e dar a perspectiva de abordagem dos personagens ao real, dão ainda uma cor especial ao espaço de ação, e servem como elemento de caracterização do tom em que o romance é cifrado. Freqüentemente os trechos descritivos alcançam uma altura de poesia, em que não é exagero vislumbrar uma influência bucólica virgiliana.

\section{A dimensão estética}

Entre as muitas possibilidades, escolhemos uma citação como exemplo do que afirmamos acima, especialmente de como a descrição 
poética do espaço ajuda a criar o tom e o clima psicológico. A citação, embora bastante longa, justifica-se por ser um momento especialmente feliz da narrativa, em que podemos não somente perceber as diferenças de técnica narrativa em relação às obras anteriores, mas principalmente notaremos um traço peculiar e muito característico de toda a obra de Osman Lins: a reescritura. Esse processo será uma constante no percurso do autor; sob uma análise mais acurada, encontraremos freqüentemente os mesmos motivos ou núcleos narrativos desenvolvidos de maneiras diversas. Este trecho que reproduziremos abaixo, dividido em quatro partes, concentra, na sua inteireza de conto e liricidade de poesia, vários aspectos mais ou menos estudados da obra de Osman Lins. Vejamos:

Teresa se sentara à porta da cozinha. A sombra da casa refrescava o quintal varrido, galinhas ciscavam ao pé da groselheira. O sol novo iluminava uma parte do varal, banhava os eucaliptos no espinhaço do monte. Por mais que vivesse, disso estava certa, sempre haveria de lembrar aquela encosta, mutável segundo as horas do dia e as épocas do ano, enevoada e triste nas manhãs de inverno, brilhante após a chuva, radiosa quando o sol nascia e tão bela nas tardes claras, quando as sombras dos eucaliptos desciam lentamente a colina, primeiro o móvel tecido da folhagem, depois as linhas paralelas dos troncos, traçando aquelas alternâncias, linhas de sombra e faixas de luz, um gradeado mágico onde seria doce caminhar e que desaparecia com o sol posto. ${ }^{4}$

Esse plácido espaço da natureza é intimamente ligado às emoções, por assim dizer, mais amplas, emoções essenciais e não sujeitas às situações conjunturais dos personagens; parece que a paisagem exprime as emoções da própria Natureza, mais do que dos personagens. Nada

\footnotetext{
${ }^{4}$ LINS, Osman. O Fiel e a Pedra. São Paulo: Summus, 1979, p. 213. A referência à mutabilidade da paisagem segundo as horas do dia e a estação do ano relembra a prática de muitos pintores de pintar exaustivamente a mesma paisagem em horas e estações diferentes. Este é um exemplo de como Osman Lins se apropria dos elementos característicos da pintura (linhas, cores, formas, luz e sombra, angulação, perspectiva, distância, etc) para pintar um quadro com palavras. Esse processo (a écfrasis literária) retornará como fundamental na construção do espaço do Retábulo de Santa Joana Carolina (Cf., sobre o tema, minha dissertação de mestrado, constante das Ref. Bibliográficas).
} 
interfere na mansuetude, na tranqüilidade do renovar-se cíclico das estações e correspondentes climas externos. É um espaço de segurança em que a alma parece dilatar-se e encontrar uma harmonia mítica jamais atingida em espaços fechados. Ao mesmo tempo, quase imperceptível, mascarado pela elevação lírica, um sentido geométrico de composição e movimento da matéria indistinta dos sentimentos orienta a evolução do olhar, do pensamento, do texto: as linhas paralelas, as linhas e faixas, o gradeado.

Já o espaço da casa, que é o espaço criado artificialmente, construído pela transformação da natureza pela técnica do homem, reflete uma história de sentimentos e emoções como que absorvidos e acumulados nas paredes, no teto, nos móveis. Parece que a alma adere às paredes da casa e aí deixa as marcas indeléveis de sua presença.

E que espécie de alma era a sua, que aderia tanto às coisas próximas? Em breve, iria embora. E, apesar de tudo, haveria de sentir saudade. Do isolamento, das verdes ondulações com suas claridades e sombras, da casa antiga. Levantara-se e espanara os móveis, polira os vidros do guarda-louça. O vago odor de salitre que havia nas paredes, o modo como a voz ressoava num salão e que nunca seria o mesmo em outra parte, os morcegos noturnos que entravam pelas clarabóias da sala e os longos serões com Bernardo, aquelas horas solitárias onde às vezes quase nem falavam, rodeados pela noite, cada um aparado na existência do outro e sabendo que a própria presença, mesmo silenciosa e talvez desesperada, era uma força de que o companheiro se envolvia, tudo lhe faria falta. E certamente isto não era um dom, aquele amor difuso e fácil fazia-a padecer, magoava-a nos momentos mais felizes. ${ }^{5}$

Na seqüência desses dois parágrafos, vemos um eco forte da filosofia de composição que orientou Os Gestos:

Apanhou o regador, pôs água limpa nas vasilhas do quintal, foi molhar no oitão a nesga de jardim. Todos os seus atos pertenciam àquela espécie de gestos transparentes, que a atenção inadvertida atravessa, jamais os fixando, porque em geral só o incomum é opaco e tem uma cor para os sentidos humanos. Mas nessa manhã as coisas recuavam: uma sombra, um ar de passado transformava-as. Todo o presente era real e já extinto, vívido e assim mesmo remoto, um tempo recordado.

${ }^{5}$ Idem, ib. 
Uma nuvem ampla e vagarosa passou diante do sol. A sombra do quintal desfez-se, as varas da cerca pareceram mais delgadas. Dois canários pousaram num ramo da groselheira. Teresa parou, voltou-se, olhou as franjas da nuvem que avançava pela encosta, seguiu devagar para o jardim. Os canários partiram rápidos, duas setas amarelas afugentadas pelo rumor dos seus passos. A grande nuvem lembrava uma galera, as claras velas estendidas. ${ }^{6}$

É sensível aqui aquela espécie de magia que transforma gestos comuns em atos rituais, especiais, porque reveladores de um conteúdo escondido à quotidianidade irreflexiva. A semelhança com o conto "Vitral" é patente no trecho abaixo:

No instante preciso em que a luz voltava, Teresa viu as rosas. Uma nascia e outra parecia cantar, as pétalas vermelhas desdobradas, tão farta em sua glória que o frágil caule pendia. O mundo esplendeu e ela sentiu-se também cheia de luz e alegre, soerguida numa onda muda que a houvesse arrebatado.

Foi só um momento. Mas aquela impressão, aquela refração dos sentidos que impunha às coisas uma existência dual, fazendo como que perdido e apenas relembrado o que ainda não deixara de ser, isto cessou. $^{7}$

São gestos e momentos reveladores, que adquirem significados especiais, porque conseguem transmitir mais do que emoções e sentimentos; são gestos que "fundem num instante único, privilegiado, os fios de cada breve composição, como se todo o passado ali se adensasse." Este trecho, que dividimos em quatro partes, lido em bloco poderia ser tomado como um conto em si, uma evolução d'Os Gestos; ou também como uma poesia sem rima, fosse outra a distribuição espacial das frases. Outro aspecto que pode até passar despercebido é a alternância do foco narrativo entre um ponto de vista objetivo e subjetivo, sempre onisciente.

\footnotetext{
${ }^{6}$ Idem, ib., p. 214. Este é apenas mais um dos exemplos do processo que reencontraremos no Retábulo: a recorrência à visualidade, a evocação de imagens, a "pintura escrita".

${ }^{7}$ Idem, ib.

${ }^{8}$ Idem, p. 5.
} 
Em relação a esse aspecto fundamental na arquitetura de qualquer texto, parece-nos interessante ressaltar a análise e o processo aprendido de Nelly Novaes Coelho sobre a alternância de foco narrativo n'O Fiel e a Pedra ${ }^{9}$ diz a estudiosa que há momentos em que o narrador vê a cena de fora (ponto de vista externo-objetivo) e momentos em que ocorre a adesão ao pensamento da personagem (externo-subjetivo); para exemplificar escolhemos aleatoriamente um trecho do capítulo XL. Colocaremos em itálico os momentos em que o ponto de vista é aderente ao pensamento da personagem:

Entristeceu-o um amargor, uma saudade daquela paz antiga. Esteve no Bilhar, deu um abraço em Bindinho, entrou numa barbearia. Perdera seu tempo, não veria Nestor. E talvez fosse melhor não vê-lo, não ceder. A tesoura estalava em sua nuca. Se não houvesse deixado o burro no Pátio do Mercado, voltaria dali e explicaria à mulher que se arrependera, que uns poucos dias a mais ou a menos... A carta falava também na criança que esperavam, mas não fazia referência a acontecimentos desagradáveis. ${ }^{10}$

O momento retratado acima não é um momento privilegiado no romance, escolhido especialmente para demonstrar nosso ponto; ao contrário, foi escolhido ao acaso somente para ilustrar o processo de alternância de foco, que acontece da primeira à última página, sempre da maneira sutil e natural que vemos acima, de modo que se não estivermos atentos, corremos o risco de tomá-lo por um processo natural de narração, quando na verdade é um artifício consciente de técnica narrativa.

\section{Os fantasmas narrativos}

No âmbito do processo de reescritura que afirmamos ser característico de Osman Lins, encontramos muitas imagens recorrentes, espécies de fantasmas narrativos que assombram o imaginário do autor (quão consciente ou inconscientemente é difícil dizer). Temos, n'O Fiel e a Pedra,

\footnotetext{
9 NOVAES COELHO, Nelly. "O Fiel e a Pedra", in O Ensino da Literatura. São Paulo: FTD, 1966.

${ }^{10}$ O Fiel e a Pedra, op. cit., p. 211.
} 
várias situações, motivos, elementos, processos que veremos refeitos ou reconfigurados no Retábulo de Santa Joana Carolina, por exemplo. O espaço apresenta já claramente uma filiação estética voltada à importação de processos e técnicas das artes visuais, claramente apropriando-se de elementos característicos de representação das artes plásticas, o que virá a se acentuar nas obras futuras, especialmente no Retábulo de Santa Joana Carolina.

Outra dimensão da criação artística de Osman Lins, não aparente no texto aos "leitores comuns" (isto é, aqueles leitores desinformados da história individual do autor), é o fundo autobiográfico que orienta a gênese de algumas situações e personagens de seus textos. Aliás a recorrência à biografia do autor como depósito inesgotável de personagens e experiências será um processo contínuo na obra de Osman Lins; em todas as obras ficcionais futuras encontraremos um pouco do autor. O espaço da ação, tratado em termos mais amplos e muito mais complexos, no Retábulo continua a ser Pernambuco; as figuras mais expressivas de ambos os textos são os modelos vivos de sua infância e adolescência: em Bernardo, seu tio Antônio Figueiredo; em Teresa, sua tia Laura; em Joana Carolina, sua avó Joana Carolina. E mesmo em Ascânio há muito da biografia do próprio autor. Futuramente em Avalovara e $A$ Rainha dos Cárceres da Grécia, teremos, só para citar um exemplo, o personagem do escritor em busca de seu romance.

Há, é claro, muitas outras imagens que são recorrentes em várias obras, tratadas de maneiras diferentes, mas sempre respondentes a uma primeira imagem originária. Provavelmente uma imagem forte e comum do interior de Pernambuco dos anos 20 e 30, a morte de crianças marcou o autor (que perdeu dois irmãos ainda crianças). É uma das imagens recorrentes em seus textos. A morte da mãe, por causa da própria experiência, é outra constante nos textos de Osman Lins. N'O Fiel e a Pedra o filho de Bernardo morre, numa cena que, embora construída de modo diferente, não deixa de lembrar a morte do filho no conto "Episódio" do livro Os Gestos. Também Joana Carolina perderá uma filha com o mesmo nome da irmã que já perdera na infância.

Mas é principalmente a morte da mãe que constitui a imagem recorrente por excelência: a mãe de Celina, em O Visitante; em Os Gestos, os órfãos nos contos "Partida" e "Navio"; no Retábulo, a morte da mãe de Joana Carolina constituirá o tema de um dos mistérios (o $\left.8^{\circ}\right)$. N'O Fiel e a Pedra, Ascânio, órfão, ouve a sofrida declaração de Bernardo: "- Morreu 
a minha mãe, Ascânio." Mas é justamente a morte da mãe de Ascânio que lembra muito de perto a experiência do autor: a mãe de Ascânio (que é prototipicamente um alter-ego de Osman) morre três semanas após o parto, enquanto a mãe de Osman Lins morreu dezesseis dias após seu nascimento, por complicações decorrentes do parto. Mas se o fato da perda da mãe marcou o escritor, não o traumatizou, como afirma ele mesmo em Evangelho na Taba:

O traço fundamental da minha vida é que, dezesseis dias depois que nasci, perdi minha mãe. (...) Não digo que tenha sido traumatizado, mas tenho a impressão que a coisa me marcou. Em conseqüência dessa morte, passei minha infância praticamente sozinho. ${ }^{11}$

A verdade é que as mães têm um lugar privilegiado na obra de Osman Lins. N'O Fiel e a Pedra, o papel da mãe de Bernardo, Lucinda, embora não ocupe muito espaço no texto, é fundamental para a constituição e compreensão do personagem. Como viu muito bem Ana Luiza Andrade ${ }^{12}$, o sonho de Bernardo, rememorando um episódio da infância, ou mais precisamente, um ritual de passagem da infância à adolescência, simboliza a travessia do protagonista em sua epopéia. É, essencialmente um ritual de passagem de um espaço, a conquista de um espaço - e, nesse sentido, é uma relação ética, do indivíduo com seu entorno, do indivíduo com o outro. Esse sonho tem de simbólico a libertação de Bernardo do poder da mãe, é mais um dos rituais de passagem. Mas a superação da prova e a libertação da obediência infantil não significam diminuição de importância da mãe; significam apenas a conquista de uma própria autonomia e a aquisição de novos valores, sem desrespeito aos valores precedentes. A figura da mãe dará lugar à da esposa, que assumirá também, na intertextualidade com a Eneida, o papel de Vênus, mãe e protetora de Enéias.

Dir-se-ia que a perda da mãe real enseja uma busca por mães fictícias, mas assim como a perda não traumatizou, a busca não obsessiona. A mãe buscada é uma figura, uma mãe de personagem, gerada pelo autor, feita de linguagem: de língua. "O escritor é alguém que brinca com o corpo da mãe."13

${ }^{11}$ Evangelho na Taba. Op. cit., p. 211.

12 Osman Lins: Crítica e Criação. Op. cit.

${ }^{13}$ BARTHES, R. O Prazer do Texto. Lisboa: Edições 70, 1976, p. 78. 


\section{A dimensão ética}

A aventura moral de Bernardo - com ou contra o mundo e seus habitantes - ultrapassa em muito seu ethos pessoal. Torna-se uma épica moderna, re-tratando uma realidade sem tempo nem espaço definidos: o abuso do poder, a opressão, a expropriação da dignidade dos oprimidos. E também o enfrentamento, dado novo na temática do autor. Recorda muito bem Ana Luiza Andrade ${ }^{14}$ o paralelismo da cena da travessia do rio por Bernardo com a situação desenvolvida no conto "Navio", evidenciando que essa comparação é fortemente indicativa da mudança de perspectiva do autor em relação ao enfrentamento da realidade, ao seu criar contra o mundo. Enquanto o personagem do conto "Navio" é um fracassado, deixa-se subjugar pelas forças (quais sejam: sociais, naturais, individuais, do destino, etc) que o aniquilam diante da negatividade do mundo, Bernardo é o oposto: não se deixa dominar pelas forças opressoras (especialmente sociais, em seu caso), e rebela-se contra o que poderia ser seu destino, já pré-determinado pelo contexto em que nasce.

Nesse sentido entendemos a chegada à maturidade, à plenitude do escritor: a aventura de Bernardo reflete, na ampliação do ethos do personagem, o ephos de um povo do qual faz parte seu criador, um homem que se reconhece igual a todos os outros, homem do povo ${ }^{15}$, homem de seu tempo, imerso na sociedade e sujeito a todas as forças que oprimem e afligem o homem brasileiro seu contemporâneo. É esse povo brasileiro que será sempre objeto de reflexão e aparecerá em suas narrativas: o homem comum, a mulher comum que, como qualquer um de nós, sempre tem algo de fantástico, de maravilhoso e mágico dentro de si.

Lins tem uma percepção muito clara dos problemas culturais do Brasi $1^{16}$, e coloca-se ao lado do povo ao reivindicar um projeto ideal de

\footnotetext{
${ }^{14}$ Op. cit.

15 "Eu sou um homem do povo. Minhas obras estão cheias de gente do povo." Osman LINS, in Evangelho na Taba, op. cit., p. 163.

${ }^{16}$ Basta conferir os subtítulos de duas de suas obras: Do Ideal e da GlóriaProblemas Inculturais Brasileiros (São Paulo, Summus Editorial, 1977), e Evangelho na Taba, Outros Problemas Inculturais Brasileiros (op. cit.); esta última publicada postumamente, organizada por Julieta de Godoy LADEIRA, mulher de Osman Lins. Cf. também o tema em um sem-número de artigos publicados em vários jornais e revistas.
} 
formação de público, que se insere num projeto maior de evolução social pela educação, como fica muito claro em seu ensaio Guerra sem Testemunhas ${ }^{17}$, e muito pontualmente colocado numa entrevista concedida ao Correio da Manhã, do Rio, publicada em 17 de setembro de 1966. Apesar de longa como citação, julgamos essencial reportá-la por ser o melhor manifesto da concepção de seriedade de atitude que, segundo Osman Lins, deve ter o escritor diante da própria obra e do público:

- Realizou você, em seu novo livro, Nove, Novena, experiências que vêm sendo indicadas como revolucionárias na literatura. Trata-se, por conseguinte, de uma obra de leitura difícil ou exigente. Ora, levando em conta as atuais condições sociais do Brasil, notadamente seu baixo índice de instrução, não acha que um livro dessa natureza acentua a dissociação entre o autor e o público?

- Não. Só há uma dissociação que um autor deve temer: é a dissociação entre si próprio e o real. E o caminho certo para essa dissociação é precisamente o academismo: o uso de fórmulas estereotipadas, que não o ajudam a captar o real e a nada conduzem. Em literatura, toda conquista árdua atinge o público, mais cedo ou mais tarde. E são essas conquistas que enriquecem o leitor, não os caminhos já conhecidos. ${ }^{18}$

Em outro trecho da entrevista, Lins reitera sua posição e explicita o motivo pelo qual não escreve textos mais "fáceis" para o público, livros sem uma dose tão grande de experimentalismos, e mais tradicionais na forma:

- Exatamente porque não desdenho o público. Porque o respeito. Em regra, os autores chamados populares não o são. Orientam o seu trabalho com objetivos comerciais, com vistas a um público que no fundo desprezam. Isto é, procuram realizar uma obra inferior ao que se consideram capazes de produzir. Porque, segundo julgam, o público não é capaz de chegar até eles. Ou seja: acham que o público está e sempre estará aquém do que eles próprios são ou julgam ser. Com esta justificativa, escrevem obras confessadamente rudimentares. Para um público, segundo eles, rudimentar. O que me sucede, como a todo escritor verdadeiro, é exatamente o contrário. Sendo um homem como

${ }^{17} \mathrm{O}$ tema perpassa toda a obra, às vezes colocado de forma explícita, outras apenas indiciado.

${ }^{18}$ Evangelho na Taba, op. cit., p. 137. 
os outros, feito da mesma carne dos outros e imerso até os ossos nos mesmos problemas que envolvem meus semelhantes, penso que me é impossível, desde que o faça honestamente, escrever algo que eles sejam incapazes de entender. Considero-os, com o mais fundo respeito, substancialmente iguais a mim. E meu respeito por eles é que me faz enfrentar todas as dificuldades da criação. Tenho de oferecer-lhes o melhor de mim mesmo, o que há de mais puro, de mais original, de mais grave em mim. E nunca, em nenhuma hipótese, as sobras do meu espírito. ${ }^{19}$

É uma literatura profundamente ética mas que jamais abrirá mão da estética, mesmo quando essa dimensão estética parece pôr em risco sua relação com a sociedade. Essa é a posição ao mesmo tempo elitista (de um ponto de vista filosófico) e popular, no sentido de que afirma que sua literatura dirige-se ao público em geral e não à elite, qualquer que seja. Osman Lins escreve para e por seu povo, porque crê absolutamente que a leitura é uma possibilidade de ampliação da estreita visão de mundo possível num universo tão pobre de cultura, tão pobre de conhecimento e de consciência. E se a literatura é capaz de abrir outros olhos ou ampliar nossa visão, a dificuldade de leitura não pode e não deve ser obstáculo para a liberdade de criação ou desculpa para o conformismo. A conquista estética não é somente elaboração técnico-artística, preciosismo e artificialidade, mas reflete sua visão de mundo. Lins afirma explicitamente que em sua literatura "reflete-se minha verdade. O que sou, o que vejo, o que sinto. Assim, os métodos que empreguei vão refletir, com o máximo

${ }^{19}$ Idem, p. 138. Nota-se uma coincidência de pensamento em relação a Michel BUTOR, que afirma: "A busca de novas formas romanescas cujo poder de integração seja maior representa pois um triplo papel com relação à consciência que temos do real: de denúncia, de exploração e de adaptação. O romancista que se recusa a este trabalho, não transtornando os hábitos, não exigindo de seu leitor nenhum esforço particular, não o obrigando a essa volta sobre si mesmo, a esse questionamento de posições há muito tempo adquiridas, tem certamente um êxito mais fácil, mas torna-se cúmplice deste profundo mal-estar, desta noite em que nos debatemos. Ele torna ainda mais rígidos os reflexos da consciência, mais difícil seu despertar, contribui para sua asfixia, tanto que, mesmo se ele tiver intenções generosas, sua obra é finalmente um veneno." In BUTOR, Michel. Repertório. Trad. Leyla Perrone-Moisés. São Paulo: Perspectivas, 1974, p. 12. 
de precisão, exatamente isso." ${ }^{20}$ Essa é, de um ponto de vista antropológico, a grande conquista do pernambucano pobre, leitor autodidata, escritor e crítico Osman Lins ("o que sou"). O Fiel e a Pedra representa a plataforma de chegada à maturidade do homem culto, não somente do escritor. Porque paralelamente à conquista literária, é já patente em seu segundo romance a aguda consciência crítica da situação em que se encontra a sociedade em que vive, pela estreiteza de visão dos políticos, pela estrutura quase feudal em que vive o nordeste brasileiro, pela imensa pobreza material e especialmente cultural dos cidadãos de todas as classes, explorados e exploradores ("o que vejo"). Esse é o retrato de uma realidade que pode e deve ser denunciada e modificada ("o que sinto"); denunciada e modificada não pelo panfletismo ideológico ou pela luta armada ou sindical, mas pela aculturação do povo, pela luta cultural que a arte, e de modo especial, a literatura, pode e deve fazer: "É através da arte - e de nenhum outro meio - que um povo se renova." ${ }^{21}$ Osman Lins evolui de um conceito de arte engajada para um de engajamento artístico: a arte tem seu papel na sociedade, e o artista não é aquele inspirado pelas musas e alheio ao mundo real, mas sim um trabalhador, um artesão, que deve ser respeitado como trabalhador e ser humano, não como sonhador ou ferramenta a ser manipulada ${ }^{22}$. Assim é que realiza como texto, como obra, sua convicção, seu ideal de literatura. A literatura é, mesmo quando cômica (o que não é o caso de Osman Lins), coisa séria. Sua função precípua é fornecer ao homem moderno, alienado, fragmentado, inconsciente, um mapa possível do labirinto, em direção à consciência. Em direção à liberdade. Porque os livros (não todo tipo de livro, mas seguramente "os de ficção", "de poesia", "de imaginação"), segundo Lins, "parecem sempre servir à liberdade", porque são "capazes de ampliar nossa visão das coisas." ${ }^{3}$

O escritor, assim como o personagem Bernardo, deve ser respeitado pelo trabalho sério que faz, e deve erguer-se contra a opressão de um

\footnotetext{
${ }^{20}$ Evangelho na Taba, op. cit., p. 134.

${ }^{21}$ Idem, p. 155.

${ }^{22}$ Ver o que diz sobre ser usado como ferramenta, no artigo "Serventes de Obra, Párias do Trabalho nas Metrópoles", em Evangelho na Taba, op. cit., p. $85-88$.

${ }^{23}$ Evangelho na Taba, op. cit., p. 63.
} 
sistema que procura tirar valor à obra literária (e artística, em geral) como fonte de aquisição de consciência crítica. A literatura é um meio de elevação do homem a uma dimensão maior do que a da pobreza, do sertão, do feudo. Para Osman Lins, sua conquista estética é também uma conquista profundamente ética. Na verdade é uma proposta e uma defesa de uma ética na estética.

\section{Referências Bibliográficas}

ADONIAS FILHO. O Romance Brasileiro de 30. Rio, Edições Bloch, 1969, 156 p. ALMEIDA, Hugo (Org.). Osman Lins: o sopro na argila. São Paulo: Nankin, 2004, 374 p.

ANDRADE, Ana Luiza. Osman Lins: Crítica e Criação. São Paulo: Hucitec, 1987, 239 p.

BARTHES, R. O Prazer do Texto. Lisboa, Edições 70, 1976, 119 p.

BUTOR, Michel. Repertório. Trad. Leyla Perrone-Moisés. São Paulo: Perspectiva, 1974, 246 p.

FERREIRA, Ermelinda (Org.). Vitral ao Sol. Ensaios sobre a obra de Osman Lins. Recife: Ed. Universitária da UFPE, 2004, 330 p.

FRITOLI, Luiz Ernani. Do Ideal e da Obra. Visualidade e Conformação do Espaço Literário em "Retábulo de Santa Joana Carolina", de Osman Lins. Dissertação de Mestrado. São Paulo: USP, 2004, 182 p.

LINS, Osman. Evangelho na Taba. Outros Problemas Inculturais Brasileiros. São Paulo: Summus Ed., 1977, 271 p.

LINS, Osman. Do Ideal e da Glória - Problemas Inculturais Brasileiros (São Paulo, Summus Editorial, 1977, 189 p.

LINS, Osman. O Fiel e a Pedra. 5. ed., São Paulo: Melhoramentos, 1976, 343 p.

LINS, Osman. Os Gestos. 2. ed., São Paulo, Melhoramentos, 1975, 148 p.

LINS, Osman. Guerra sem Testemunhas: o escritor, sua condição e a realidade social. São Paulo: Ática, 1974, 224 p.

NITRINI, Sandra. Poéticas em Confronto. Nove, novena e o Novo Romance. São Paulo/Brasília: Hucitec, 1987, 289 p.

NOVAES COELHO, Nely. "O Fiel e a Pedra", in O Ensino da Literatura. São Paulo: FTD, 1966, 546 p. 